\title{
Comparative Study of the Excavation Damage and Rockburst of the Deeply Buried Jinping II Diversion Tunnels Using a TBM and the Drilling-Blasting Method
}

\author{
Jing Yang, ${ }^{1,2}$ Xing-Guo Yang, ${ }^{1}$ Jia-Wen Zhou $\mathbb{D}^{3},{ }^{3}$ Yong Liu, ${ }^{2}$ \\ Bao-Shun Dong, ${ }^{4}$ and Hai-Bo $\mathrm{Li} \mathbb{C}^{1}$ \\ ${ }^{1}$ College of Water Resource and Hydropower, Sichuan University, Chengdu 610065, China \\ ${ }^{2}$ Huaneng Tibet Yarlung Zangbo River Hydropower Development and Investment Co., Ltd., Chengdu 610061, China \\ ${ }^{3}$ State Key Laboratory of Hydraulics and Mountain River Engineering, Sichuan University, Chengdu 610065, China \\ ${ }^{4}$ PowerChina Huadong Engineering Co. Ltd., Hangzhou, Zhejiang 311122, China
}

Correspondence should be addressed to Hai-Bo Li; hbli@scu.edu.cn

Received 14 August 2020; Revised 22 November 2020; Accepted 27 November 2020; Published 9 December 2020

Academic Editor: Fengqiang Gong

Copyright $\odot 2020$ Jing Yang et al. This is an open access article distributed under the Creative Commons Attribution License, which permits unrestricted use, distribution, and reproduction in any medium, provided the original work is properly cited.

\begin{abstract}
The rock mass failure induced by high in-situ stresses during the excavation of deep diversion tunnels is one of the key problems in the construction of the Jinping II Hydropower Station. Based on the results of acoustic wave tests and rockburst statistical analysis conducted, this study focuses on the excavation damaged zone (EDZ) and rockburst events in the Jinping II diversion tunnels excavated using the tunnel boring machine (TBM) method and the drilling-blasting method. The unloading failure mechanism and the rockburst induced by the two different excavation methods were compared and analyzed. The results indicate that, due to the different stress adjustment processes, the degree of damage to the surrounding rock mass excavated using the drilling-blasting method was more serious than that using the TBM method. The EDZ induced by the TBM was usually distributed evenly along the edge of the excavation surface. While, the drilling-blasting method was more likely to cause stress concentration, resulting in a deeper EDZ in local areas. However, the TBM excavation method can cause other problems in high in-situ stress areas, such as strong rockbursts. The drilling-blasting method is more prone to structural controlled failure of the surrounding rock mass, while the TBM method would induce high stress concentration near the edge of excavation and more widely distributed of stress adjustment induced failure. As a result, the scale and frequency of the rockburst events generated by the TBM were significantly greater than those caused by the drilling-blasting method during the excavation of Jinping II diversion tunnels. The TBM method should be used carefully for tunnel excavation in high in-situ stress areas with burial depths of greater than $2000 \mathrm{~m}$. If it is necessary to use the TBM method after a comprehensive selection, it is suggested that equipment adaptability improvement, advanced prediction, and prediction technology be used.
\end{abstract}

\section{Introduction}

The excavation of tunnels would cause stress redistribution and concentration, unloading rebound in the surrounding rock mass, and the initiation and propagation of microcracks, which usually resulted in the excavation damaged zone (EDZ) or rockburst [1]. The EDZ significantly influences the overall stability of tunnels and increases the probability of failure in the underground caverns $[2,3]$. Many scholars have conducted research on this. The tests conducted by the Canadian Energy Corporation's (AECL) underground laboratory (URL) show that failure occurred in the surrounding rock within $0.5 \mathrm{~m}$ of the excavation range, and the elastic modulus of the surrounding rock within $2 \mathrm{~m}$ decreased by $10-20 \mathrm{GPa}$ [4]. Wu et al. proposed a relationship between the unloading strain and the cumulative crack opening displacement [5]. Maxwell et al. conducted tests at the URL and found that the wave speeds in the sidewall, crown, and bottom of the tunnel were reduced, and they tried to use the microvelocity to excavate the 
surrounding rock damage zone [6]. Jiang et al. proposed an intelligent optimization method for the excavation of the cavern, which greatly reduced the total damage area and the brittle failure of the surrounding rock [7]. By studying the time-varying damage to the rocks, a new damage viscoelastic-plastic model was proposed, which provides a theoretical basis for the restoration of damaged rocks [8].

Different excavation methods cause different categories and amounts of rock damage. Sato used the armtype roadheader to study the disturbance of the surrounding rock and found that the width of the EDZ in soft tertiary sedimentary rocks is $0.3 \mathrm{~m}$, which is smaller than that caused by the drilling-blasting method. This method can effectively limit the degree of damage to the surrounding rock [9]. Barton studied the relationship between the efficiency of the TBM and the drilling-blasting methods for different rock qualities [10]. More studies have found that the drilling-blasting method is more prone to structural plane failure, while the TBM method is more possible to concentrated, the displacement and plastic zone are distributed more widely, and the secondary failure length is larger [11-13].

Rockburst is another important problem in the excavation of deeply buried surrounding rock with a high in-situ stress. Jiang et al. studied the rockburst phenomenon using the numerical simulation method and developed a new local energy release rate (LERR) index, which can satisfactorily predict the depth of the outburst pit and the intensity of the rockburst, providing a new method to evaluate the rockburst orientation in deep underground projects [14]. Zhuang et al. conducted realtime monitoring of microvibration events and rockburst during the TBM excavation of Jinping II diversion tunnel $1^{\#}$ and found that the top guide tunnel excavation method can effectively reduce the risk of rockburst during TBM tunnel excavation [15]. It was found that the unloading rate has an important influence on the degree and failure models of rockburst during the excavation [16-18]. When the unloading rate is high (excavation by the drillingblasting method), the rock is prone to strainburst. On the other hand, as the unloading rate decreases (such as excavation by the TBM method), the failure mode changes from strainburst to spalling [19-22].

The Jinping II Hydropower Station has the largest diversion tunnel group in the world, which is quite representative in underground engineering in southwest China. During the excavation period of diversion tunnels, the drilling and blasting method and the TBM method were adopted simultaneously, which makes it possible to compare the quality of unloading rock mass between the two methods. In this study, the Jinping II diversion tunnels were taken as an example. Based on the results of the field acoustic tests and the investigation of rockburst events, this study compared the unloading damage to the surrounding rock mass caused by the drilling-blasting method and the TBM method during the excavation of a deeply buried tunnel under high in-situ stress. The impacts of the two excavation methods on the surrounding rock mass in a high in-situ stress environment were also studied, providing information on the most suitable methods for the excavation of the deeply buried long diversion tunnels in southwestern China, especially in the plateau area.

\section{Project Background}

The Jinping II Hydropower Station is located on the Yalong River, Sichuan Province, southwestern China (Figure 1). The station makes use of the natural drop at the river bend to generate electricity using a group of inlet tunnels cut into the bend [23]. The project is mainly composed of a headwork sluice dam, a diversion system, and an underground powerhouse. The diversion system includes 4 parallel diversion tunnels crossing Jinping Mountain, with an average length of $16.7 \mathrm{~km}$, from the water inlet to the upstream surge chamber. The distance between the tunnels is $60 \mathrm{~m}$, and the direction of the tunnel axes is $N 58^{\circ} \mathrm{W}$. The slope of the diversion tunnels is as gentle as $3.65 \%$, and the elevation ranges from $1618.00 \mathrm{~m}$ at the bottom of the inlet to $1564.70 \mathrm{~m}$ at the upstream surge chamber.

2.1. Geological Conditions. The engineering area of the Jinping II Hydropower Station is geotectonically located in the southeastern part of the Songpan Ganzi geosynclinal fold belt. Under the control of the NWW-SEE directional stress field, a series of nearly N-S trending compressional or compression-shear faults with high dip angles and close complex folds were formed, accompanied by NWWtrending tensile or tensional-shear faults. From east to west, the diversion tunnel passes through the Yantang Formation marble $\left(T_{2 \mathrm{y}}\right)$, the Baishan Formation marble $\left(T_{2 \mathrm{~b}}\right)$, the Upper Triassic sand slate $\left(T_{3}\right)$, the Heterogonne Formation marble $\left(T_{2 \mathrm{z}}\right)$, the Lower Triassic chlorite schist, and the metamorphic medium fine sandstone $\left(T_{1}\right)$. The dip of the strata is steep, and the strike is in accordance with the direction of the main structural line (Figure 2(a)). The surrounding rock mass is hard and brittle. A hydro-electric surrounding rock classification standard $(\mathrm{HC})$ was used to classify the surrounding rocks, according to the standard of code for water resources and hydropower engineering geological investigation (GB50287-99) [24]. The rock mass surrounding the Jinping II diversion tunnel area is mainly classified as type III and type II, accounting for $53.5 \%$ and $37.5 \%$, respectively. The type IV and V surrounding rock masses are less abundant, accounting for $8.1 \%$ and $0.9 \%$, respectively. Among them, the percentage of the degraded types $\left(\mathrm{II}_{\mathrm{b}}, \mathrm{III}_{\mathrm{b}}, \mathrm{IV}_{\mathrm{b}}\right.$, and $\mathrm{V}_{\mathrm{b}}$ ) of surrounding rock masses resulting from rockburst is $19.8 \%, 7.2 \%, 5.4 \%$, and $0.9 \%$, respectively. In general, the NNE-trending bedding joints and the EW-trending tensional-shear joints are mostly well developed, with the former being mostly closed and the latter being mostly open. The joints are parallel, and their spacing increases with burial depth, but they are mostly $20-40 \mathrm{~cm}$ apart. The steep joints have dip angles of $60-84^{\circ}$. The joints are slightly open and mostly filled with calcium cement.

The crust in the engineering area has been uplifted rapidly for a long time, while the Yalong River cuts down 


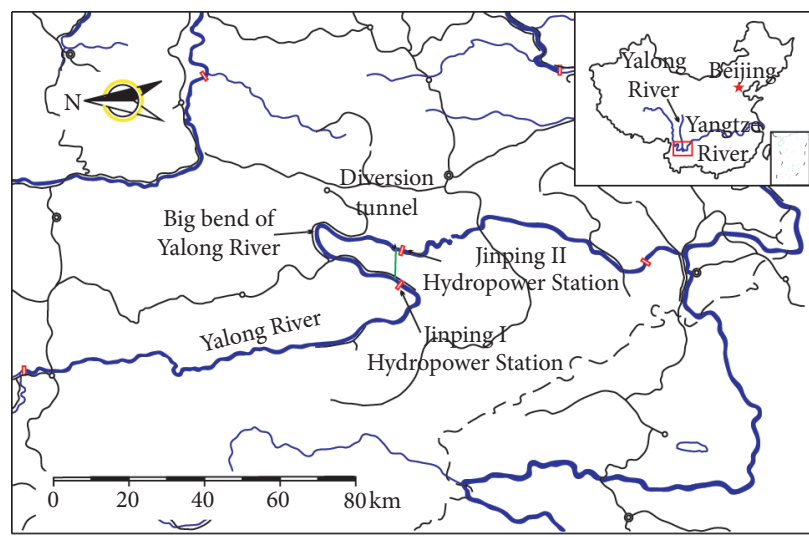

(a)

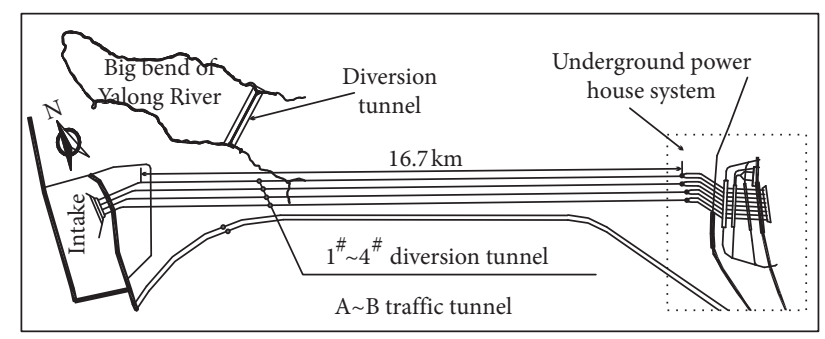

(b)

FIgURE 1: Location of the Jinping II diversion tunnels: (a) location of the Jinping II Hydropower Station and (b) location of the diversion tunnels.

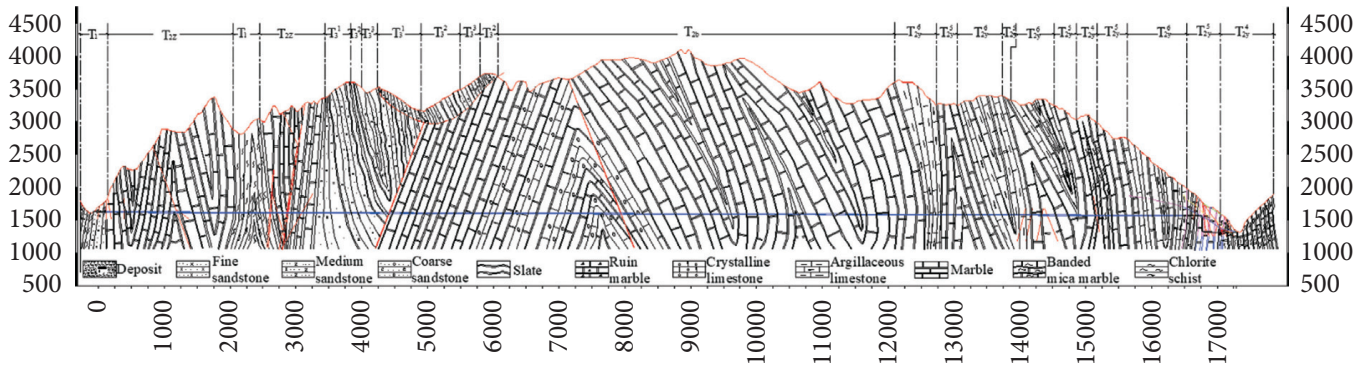

(a)

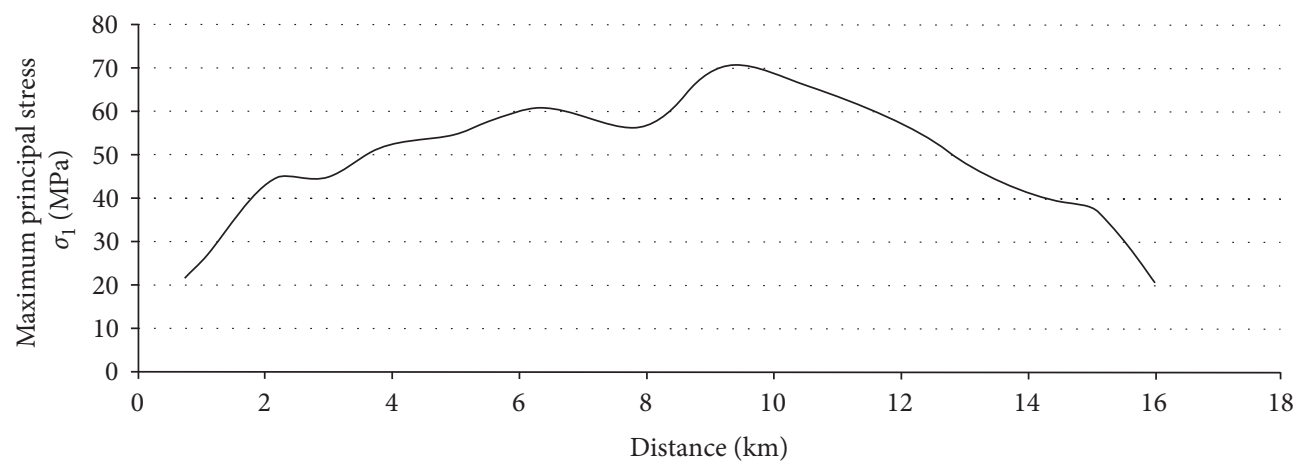

(b)

Figure 2: Geological conditions of the Jinping II diversion tunnels: (a) typical geological section (along the axis of $1^{\#}$ diversion tunnel) and (b) maximum principal stress along the axis of traffic tunnel A.

sharply through the high mountain, deep valleys, and steep slopes. This area has experienced rapid changes in topography, and thus, a large amount of energy has been stored at depth. After the rapid uplift of the crust, some of the energy was released through denudation, but the remaining energy is difficult to release. Therefore, this area is a stress concentration area with a huge reserve of elastic energy. Most of the diversion tunnels have burial depths of $1500-2000 \mathrm{~m}$, and the largest depth is $2525 \mathrm{~m}$. According to the inversion regression analysis of the $3 \mathrm{D}$ initial stress field in the engineering area, the in-situ stress is dominated by gravitational stress, and the maximum and minimum principal stresses are $70.1 \mathrm{MPa}$ and $30.1 \mathrm{MPa}$, respectively. An investigation of the in-situ stress distribution along the axis was carried out in the traffic tunnel parallel to the diversion tunnel. According to the results, the peak value of the maximum principal stress occurs about $9 \mathrm{~km}$ away from the inlet where the burial depth is largest (Figure 2(b)). As the curve of the maximum principal stress in Figure 2(b) shows, the maximum principal stress is generally consistent with the change in the burial depth of the diversion tunnels. Under the influence of a high in-situ stress, many rockburst 
events occurred during the excavation of the traffic tunnel [25].

Due to the steep valley slopes, steeply dipping rock strata, and strong unloading of the surface rock mass, the unloading fractures in the engineering area are generally prone to forming original structural fractures and bedding fractures with steep dip angles. Based on the existing cave exploration results, in the studied tunnel section, the horizontal depth (the distance from the tunnel to the slope surface in the horizontal direction) of the strong unloading zone is less than $154 \mathrm{~m}$ and that of the weak unloading zone is $135-163 \mathrm{~m}$. The in-situ stress around the diversion tunnels is high, and a large amount of strain energy is stored in the surrounding rock mass as a result of long-term geological processes. Under these conditions, tunnel excavation leads to the instantaneous release of stress, which can cause serious unloading deformation and damage to the surrounding rock mass.

2.2. Construction. A construction scheme combining the drilling-blasting method and the TBM method was adopted for the excavation of the diversion tunnels. Specifically, the eastern section of diversion tunnel $1^{\#}$ (stake from K15 + 795 to $\mathrm{K} 9+936 \mathrm{~m}$ ) and the eastern section of diversion tunnel $3^{\#}$ (stake from $\mathrm{K} 15+903$ to $9+607 \mathrm{~m}$ ) were excavated using a TBM, while the rest of the tunnels were excavated using the drilling-blasting method. The section excavated using a TBM was circular, with a diameter of $12.4 \mathrm{~m}$. The diameter of the tunnel section containing a concrete lining was $11.2 \mathrm{~m}$, and the flow velocity was $4.72 \mathrm{~m} / \mathrm{s}$. The tunnel section excavated using the drilling-blasting method is horseshoe-shaped, with a diameter of $13 \mathrm{~m}$. The diameter of the section containing a concrete lining is $11.8 \mathrm{~m}$, and the flow velocity is $4.11 \mathrm{~m} / \mathrm{s}$. The diameter of the section supported by shotcrete and bolting is $12.6 \mathrm{~m}$, and the flow velocity is $3.77 \mathrm{~m} / \mathrm{s}$ (Figure 3).

The TBM used in diversion tunnel $1^{\#}$ was a $410-319$ open type TBM manufactured by Robbins, USA. The cutter is flat and straight with a diameter of $17^{\prime \prime}$ and $19^{\prime \prime}$, and it has a high rock-breaking efficiency and a good abrasive resistance. The spacing between the central cutters is $100 \mathrm{~mm}$, and that between the panel cutters is $86.5 \mathrm{~mm}$, which is a universal cutter spacing. The support system of the TBM is divided into three zones (L1, L2, and L3). L1 is the emergency safety support zone where bolting, bar-mat reinforcement, steel arches, steel tiles, and shotcrete are used. L2 is the main support zone where bolting and shotcrete are used. L3 is the reinforcing support zone where shotcrete is used. The TBM used in diversion tunnel $3^{\#}$ was an open type TBM manufactured by Herrenkmecht, Germany. As with the Robbins 410-319, this TBM also has a straight, flat cutter with a diameter of $19^{\prime \prime}$, and the support system also has three zones. However, the powers and lengths of the two TBMs are different [26].

\section{Unloading Damage Analysis}

3.1. Detection of the Excavation Damaged Zone in the Surrounding Rock Mass. In order to study the quality of the rock mass surrounding the diversion tunnels during the excavation using the TBM or drilling-blasting method and to analyze the excavation damaged zone depth of the rock mass, the acoustic wave detection method was implemented. The acoustic wave detection method is based on the theory of elastic wave propagation in a solid medium. By means of manual shaking, sound waves are induced in the medium, and the modulated sound waves are received at a distance. In addition to determining the physical properties, this method can be used to confirm the excavation damaged zone (EDZ) after observing and analyzing the velocity along the test hole $[1,5,27]$. The wave velocity decreases with increasing acoustic impedance and crack development, and it increases with increasing rock mass stress and density [28]. The EDZ in the surrounding rock was acquired by the measured longitudinal wave velocity of the acoustic wave and the drawn Vp-L curve (the relationship curve between acoustic wave velocity and borehole depth). According to the standard for construction technical specifications on rockfoundation excavating engineering of hydraulic structures (DL/T5389-2007), the range of the EDZ is determined based on the variation characteristics of the Vp-L curve (from orifice to the mutation point of the first wave velocity) [29]. The monitoring section of the surrounding rock was arranged at intervals of $50 \mathrm{~m}$ in each tunnel section, and the acoustic wave velocities of the rock mass surrounding the tunnels were determined within a certain depth range (generally no less than 3 times the tunnel's diameter). In each section, 3-8 testing holes were arranged in the crown, left and right arches, and sidewalls (as shown in Figure 4). The diameter of the testing holes was $50-60 \mathrm{~mm}$, and their depth was controlled to no less than $40 \mathrm{~m}$. Due to the large diameter of the diversion tunnel and the deep drilling depth, it was difficult to ensure that each group of boreholes was parallel, and thus, the test accuracy of the transonic wave method cannot be guaranteed. Therefore, the thickness of the EDZ in rock mass surrounding the tunnel was measured using the single-hole acoustic testing method. The test instrument was an RS-ST01C type acoustic wave meter produced by the Wuhan Yanhai Company, China, which uses one shot and two receivers and makes continuous observations along the whole wall from bottom to top. The single-hole acoustic wave measuring point spacing was controlled at no more than $20 \mathrm{~cm}$, and the measuring point spacing, which was within $10 \mathrm{~m}$ of the test hole, was $10 \mathrm{~cm}$.

3.2. Comparative Analysis of the EDZ Caused by the TBM or Drilling-Blasting Method. The excavation of the water diversion tunnel led to the relaxation of the radial stress and induced new cracks, and this state reduces the acoustic wave velocity of the surrounding rock. Two typical acoustic wave curves for a section of $\mathrm{K} 16+500 \mathrm{~m}$ in water diversion tunnels $1^{\#}$ and $2^{\#}$ are shown in Figure 5. As can be seen, in the $\mathrm{K} 16+500 \mathrm{~m}$ section of water diversion tunnel $1^{\#}$, the acoustic wave curve exhibits a step-like pattern. Near the edge of the excavation, the rock mass was highly damaged, and the acoustic wave velocity was as low as $1970 \mathrm{~m} / \mathrm{s}$. As the test hole depth increased, the disturbance of the surrounding 
rock decreased, and the acoustic wave velocity gradually increased. At a depth of $1.8 \mathrm{~m}$, the acoustic wave velocity reached $6100 \mathrm{~m} / \mathrm{s}$, and the surrounding rock was relatively complete. After this, the acoustic wave velocity changed little. Similarly, the acoustic wave curve for section $\mathrm{K} 16+500 \mathrm{~m}$ in water diversion tunnel $2^{\#}$ also exhibited a step-like curve. The volatility increased with increasing test hole depth, and finally, it reached a relatively stable value at a depth of $2.2 \mathrm{~m}$. According to the test standard, the depths of the EDZs in section $\mathrm{K} 16+500 \mathrm{~m}$ of water diversion tunnels $1^{\#}$ and $2^{\#}$ are $1.8 \mathrm{~m}$ and $2.2 \mathrm{~m}$, respectively.

In order to further illustrate the different effects of the TBM method and the drilling-blasting method on the unloading damage to the rock mass surrounding the diversion tunnels, the acoustic wave velocities in the surrounding rock mass near three typical test sections $(\mathrm{K} 14+500 \mathrm{~m}, \mathrm{k} 15+200 \mathrm{~m}$, and $\mathrm{k} 15+600 \mathrm{~m})$ of water diversion tunnels $1^{\#}-4^{\#}$ were acquired. The results are shown in Figure 6. As can be seen, the depths of the EDZs were usually $1-4 \mathrm{~m}$. Near the K14 $+500 \mathrm{~m}$ section, the maximum depths of the EDZs in water diversion tunnels $1^{\#}-4^{\#}$ are $2.6 \mathrm{~m}, 2.8 \mathrm{~m}, 3.0 \mathrm{~m}$, and $3.2 \mathrm{~m}$, respectively; and the average depths of their EDZs are $1.88 \mathrm{~m}, 2.53 \mathrm{~m}, 2.44 \mathrm{~m}$, and $1.8 \mathrm{~m}$, respectively (Figures $6(\mathrm{a})-6(\mathrm{~d})$ ). The tested depths of the EDZs in the surrounding rock mass near sections $\mathrm{K} 15+200 \mathrm{~m}$ and $\mathrm{K} 15+600 \mathrm{~m}$ are similar. The average depth of the EDZ for rock mass excavated by the TBM $\left(1^{\#}\right.$ and $3^{\#}$ water diversion tunnels) is $1.82 \mathrm{~m}$, about $6.67 \%$ less than that of rock mass excavated by the drilling-blasting method with the average depth of the EDZ of $1.95 \mathrm{~m}\left(2^{\#}\right.$ and $4^{\#}$ water diversion tunnels). This indicates that the unloading damage in the rock mass caused by the TBM method (water diversion tunnels $1^{\#}$ and $3^{\#}$ ) is lighter than that caused by the drilling-blasting method (water diversion tunnels $2^{\#}$ and $4^{\#}$ ). Furthermore, it can be seen that the EDZs in the surrounding rock mass caused by the drilling-blasting method (water diversion tunnels $2^{\#}$ and $4^{\#}$ ) are significantly greater in the left and right arch foots than those in the crown and sidewalls (e.g., Figures 6(d), 6(j), and 6(l)), and the deepest EDZ reached $4.8 \mathrm{~m}$, while those caused by the TBM method (water diversion tunnels $1^{\#}$ and $3^{\#}$ ) are evenly distributed along the edge of the excavation surface. This indicates that the use of the drilling-blasting method is more likely to cause stress concentration in the local area of the tunnel (usually the arch foot), resulting in a deeper EDZ.

3.3. Mechanism Analysis. According to the comparative analysis of the EDZs caused by the TBM and drillingblasting methods, the degrees of damage to the surrounding rock mass caused by the drilling-blasting method are more serious than those caused by the TBM method. Since the water diversion tunnels of $1^{\#} \sim 4^{\#}$ were arranged in parallel from north to south successively with a relatively shorter spacing of $60 \mathrm{~m}$ (Figure 3). Their geological conditions are basically the same between one another. The difference is mainly due to the different stress adjustment processes in the surrounding rock mass caused by the different excavation methods.
As shown in Figure 7(a), before the excavation of the diversion tunnel, the natural rock mass is usually in a state of three-dimensional compression. During the excavation process, the initial geometry of the rock mass is changed by the TBM or drilling-blasting method. The stress constraint on the surrounding rock mass is quickly removed, the stress state changes from a triaxial stress state to a high biaxial stress state (radial stress $\sigma_{3} \approx 0$ ), and the tangential stress $\sigma_{1}$ is concentrated at the edge of the excavation surface. For the different disturbance modes of the surrounding rock mass, the different changes in the stress state lead to different rebound deformations of the excavation surface in different depth ranges, which causes the surrounding rock mass to produce tensile stress parallel to the unloading deformation direction. There are microcracks, microdefects, and/or microholes in the rock mass, which are the most concentrated areas of the unloading differential deformation, and the tensile stress is concentrated after the excavation disturbance. This increases the shear stress in the stress concentration areas, such as at the crack tips, and the stress field changes accordingly from a compressive shear stress state to a tensile shear stress state. After the unloading differential deformation reaches a certain degree, the radial stress $\sigma_{3}$ transforms into tensile stress. It is under the action of this combined tension shear stress that the microcracks in the surrounding rock continue to expand and penetrate, reflecting the unloading damage of the surrounding rock mass.

As shown in Figures 7(b) and 7(c), different excavation methods would induce different categories and amounts of EDZs. As for the drilling-blasting excavation method, the cracks preferentially expand in the direction of the line connecting the blast holes, the rock fragments fall away, forming a new excavation face, and the unloading process occurs. In a short period of time, the radial stress of the original rock mass is relieved, leading to the over relaxation of the surrounding rock mass. The release of the deformation energy in a short period of time leads to serious rebound deformation and strong stress concentration in the arch foots, inducing deep EDZs in the local areas. In contrast, as for the TBM excavation method, the cutterhead penetrates into the rock mass under the action of thrust, forming a high stress crushing area and radial cracks at the tool's tip and sides. Under the action of torque, the cutterhead expands the crushing area, causing the crack to expand and form rock fragments, which causes little disturbance of the surrounding rock. The deformation energy stored in the rock mass can be released gradually, and the stress-strain curve of the surrounding rock is smooth. Since the stress adjustment lasts for a long time, the stress concentration is relieved, and the unloading damage is relatively small.

\section{Rockburst Analysis}

Due to the large burial depth, high in-situ stress, and the hard and relatively complete rock mass, rockburst is very prominent during excavation. During the construction process, the relevant data for the rockbursts in diversion tunnels $1^{\#}-4^{\#}$ were collected over time, providing a basis for 


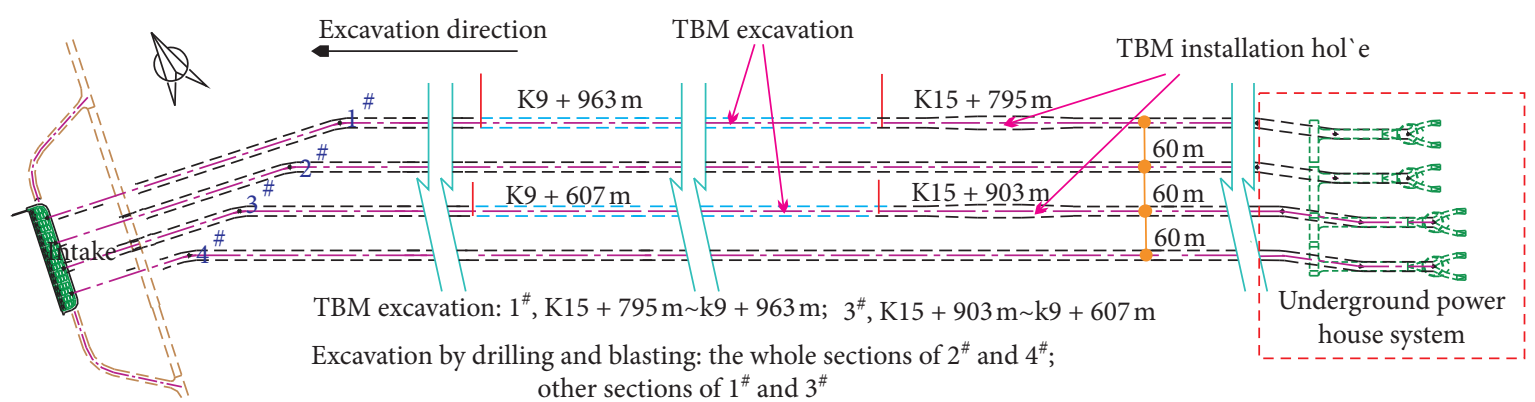

(a)

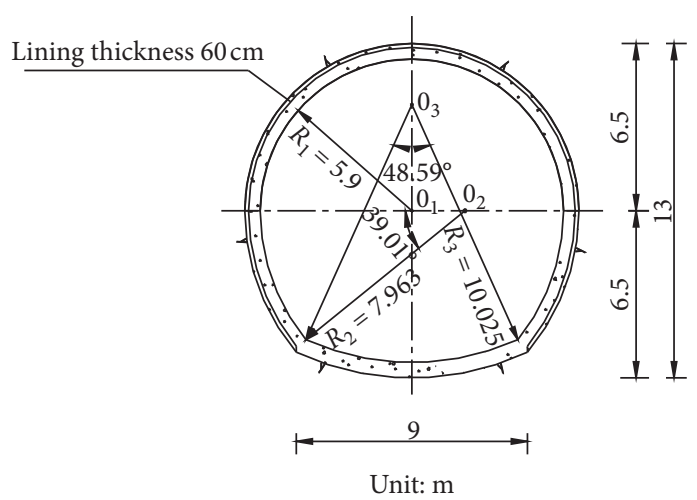

(b)

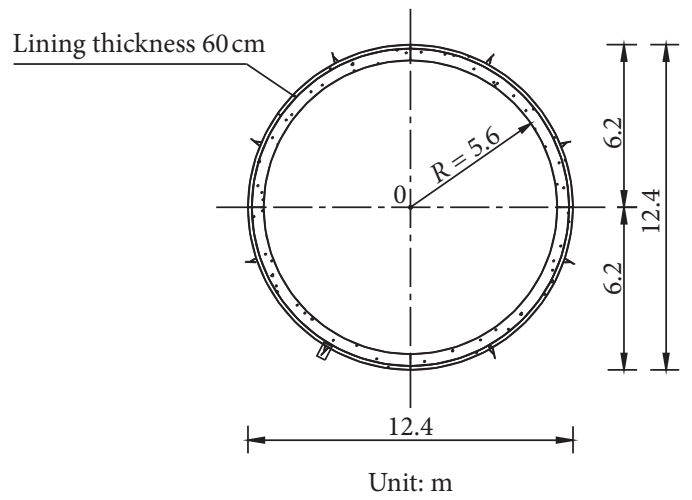

(c)

FIgURE 3: Construction design drawing of Jinping II diversion tunnels: (a) excavation sections of the diversion tunnel by the TBM or drilling-blasting method, (b) typical cross section of the diversion tunnel excavated by the TBM, and (c) typical cross section of the diversion tunnel excavated by drilling and blasting.

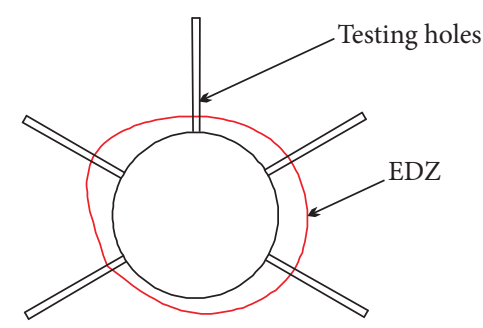

(a)

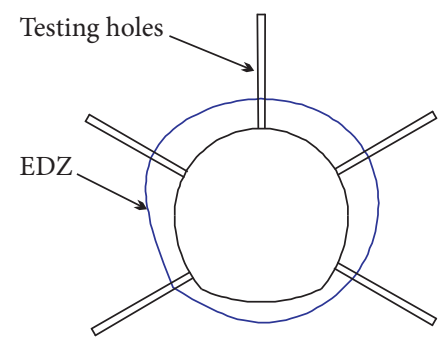

(b)

FIGURE 4: A schematic diagram of testing holes arrangements in diversion tunnels: (a) for TBM sections and (b) for drilling-blasting sections. 


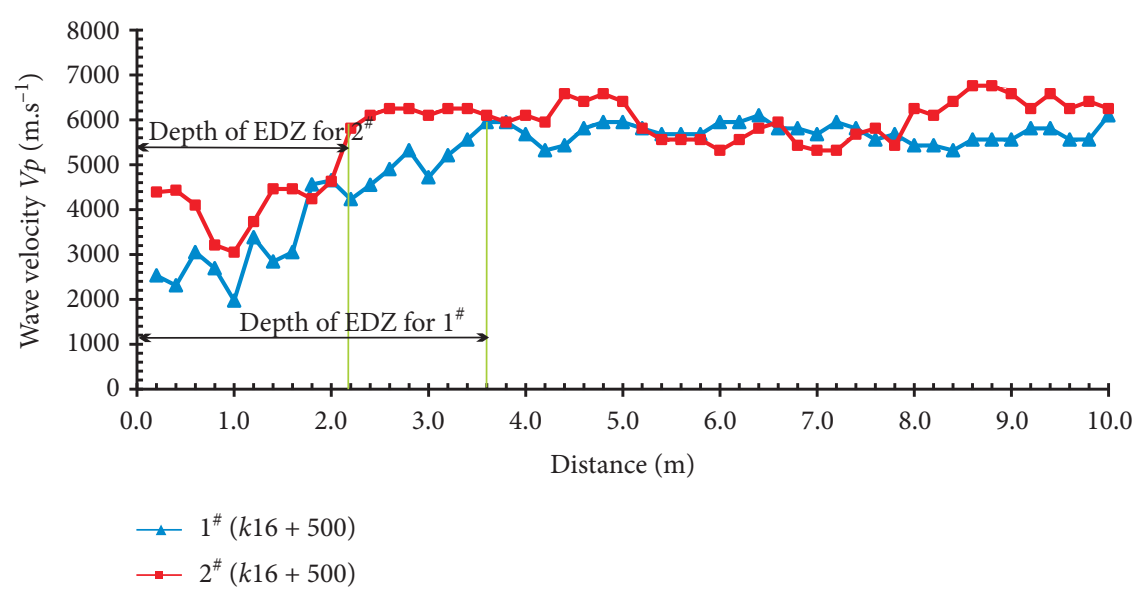

Figure 5: Typical acoustic monitoring results.

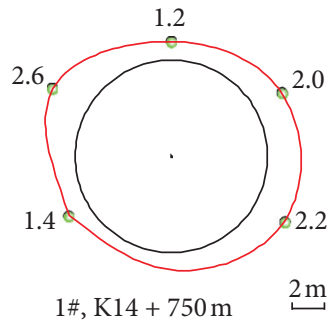

(a)

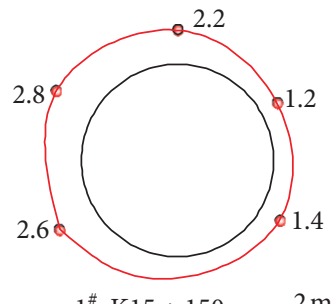

$1^{\#}, \mathrm{~K} 15+150 \mathrm{~m} \quad 2 \mathrm{~m}$

(e)

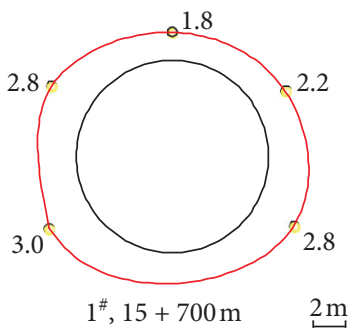

(i)

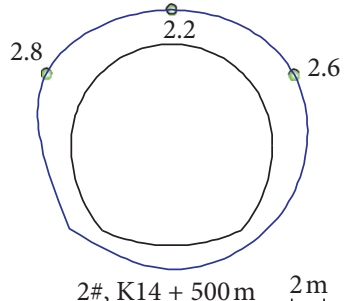

(b)

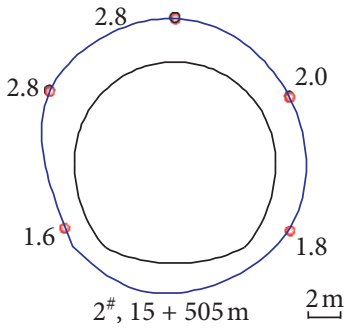

(f)

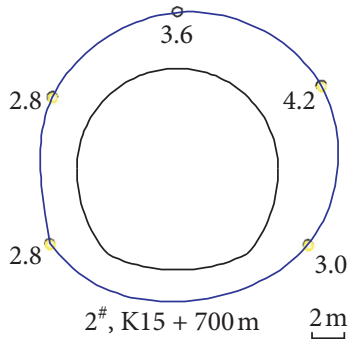

(j)

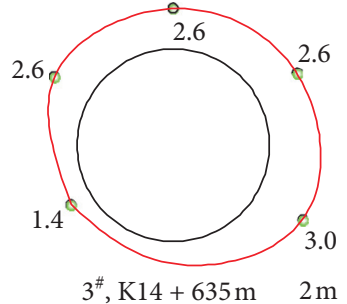

(c)

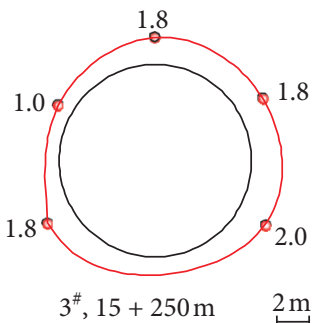

(g)

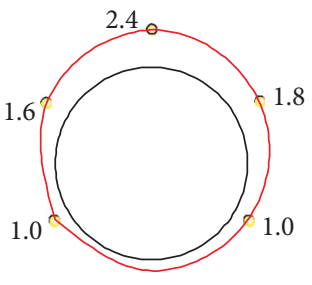

$3^{\#}, 15+740 \mathrm{~m}$

(k)

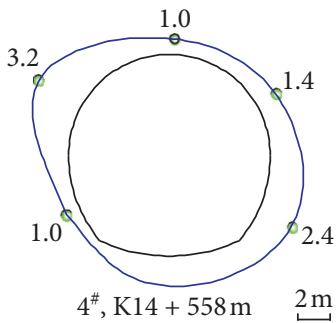

(d)

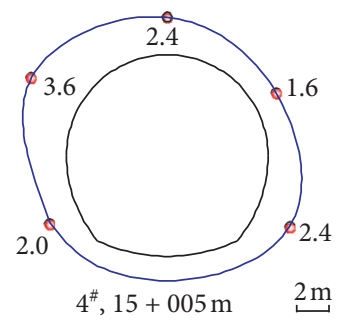

(h)

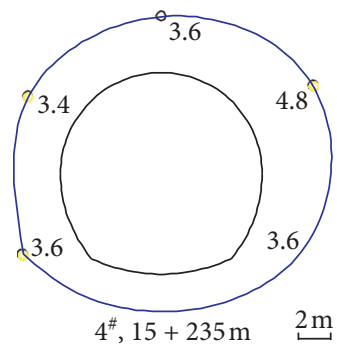

(l)

Figure 6: Typical cross sections of relaxation ranges measured by acoustic monitoring for rock mass of $1^{\#}-4^{\#}$ diversion tunnel: (a) (d) nearby $\mathrm{k} 14+500 \mathrm{~m},(\mathrm{e}) \sim(\mathrm{h})$ nearby $\mathrm{k} 15+200 \mathrm{~m}$, and (i) (l) nearby $\mathrm{k} 15+600 \mathrm{~m}$.

the analysis of the rock mass failure caused by the different excavation methods.

4.1. Rockburst Failure Analysis. The rock mass failure induced by the high in-situ stresses during the excavation of deep diversion tunnels is one of the key problems faced in the construction of the Jinping II Hydropower Station. It not only threatens the safety of the workers but also seriously affects the construction process. Based on a large amount of survey data from the construction site, the types, scale, and failure mechanism of the rockburst events that occurred during the excavation process of the diversion tunnels 1\#-4\# (excavated by using TBM method or drilling-blasting 

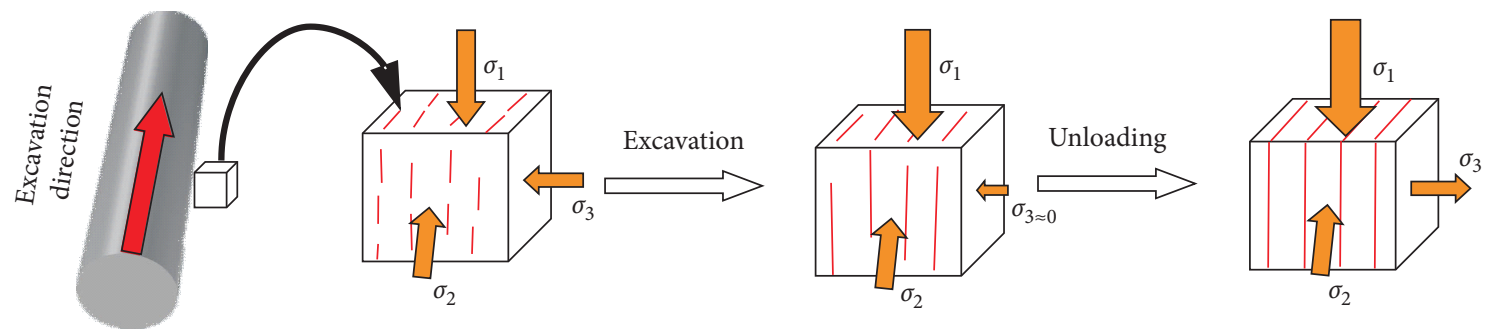

(a)

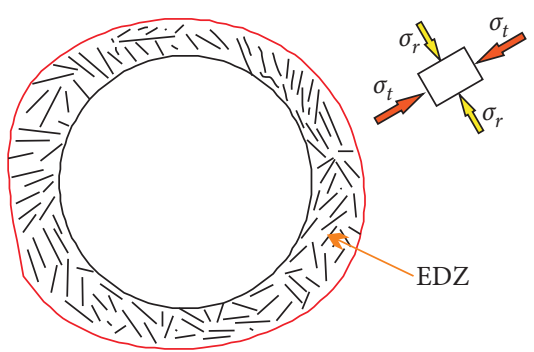

(b)

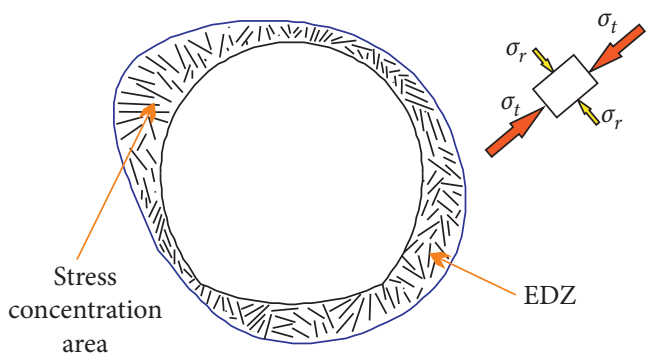

(c)

FIgURE 7: Unloading failure mechanism by different excavation methods: (a) unloading and failure process during the excavation, (b) the EDZ induced by the TBM, and (c) the EDZ induced by drilling-blasting.

method) were studied. Figure 8 shows several typical types of rockburst failure that occurred during the excavation. Figure 8(a) shows the extrusion and slabbing of the left arch foot of diversion tunnel $1^{\#}$ (section $\mathrm{k} 14+318-328 \mathrm{~m}$ ). Slabbing caused by the stress concentration was also observed on the right arch foot of diversion tunnel $4^{\#}$ (section $\mathrm{k} 13+255-270 \mathrm{~m}$ ) (Figure 8(b)). Figure 8(c) shows the folding and belling of the rock mass of the left sidewall of diversion tunnel $\mathrm{l}^{\#}$ (section $\mathrm{k} 14+789-800 \mathrm{~m}$ ). In addition, structural plane controlled failure occurred on the right arch of diversion tunnel $2^{\#}$ (section $\mathrm{k} 14+580 \mathrm{~m}$ ) (Figure 8(d)).

Rockburst is a common failure phenomenon that occurs during the excavation of the surrounding rock mass in high ground stress tunnels. Many scholars have provided different explanations for the different types of rockburst failure. Hoek et al. reported that rockburst is the result of the shear failure of the rock mass surrounding a tunnel in a high ground stress area [30]. Russenes believed that rockburst is a rock failure behavior that is accompanied by sound and produces flaking or even ejection, forming a new structural plane [31]. Ortlepp et al. expounded the occurrence and failure mechanism of rockbursts and pointed out that the occurrence and failure mechanism may be different for different source types [32]. Xu et al. pointed out that the model for rockburst energy accumulation, dissipation, and rock fracturing depends on the comprehensive action of the rock mass structure, its nature, the geological structure, and hydrogeology [33].

The mechanical process of extrusion and slabbing is shown in Figure 9(a). At the moment of tunnel excavation, the radial stress within the surrounding rock mass near the edge of the excavation surface decreases, and the tangential stress increases simultaneously, so it is basically in a biaxial stress state. In this stress state, the surrounding rock mass rebounding deforms toward the free face. The sudden unloading and differences between rebound lead to tension stress concentrated at the tips of the pre-existing microcrack in near surface surrounding rock mass and which induces tensile fractures parallel to the direction of the tangential stress. Those tensile fractures separate the rock mass into a potential shear deformation body roughly parallel to the tunnel wall $[1,3,34]$. The deformation body is mainly affected by the tangential force at both ends and the radial support force of the parent rock mass. With the gradual increase in the tangential stress, the deformation body continuously accumulates elastic strain energy and gradually deforms toward the center of the tunnel. When the strain energy reaches a certain value, the occlusion and friction 


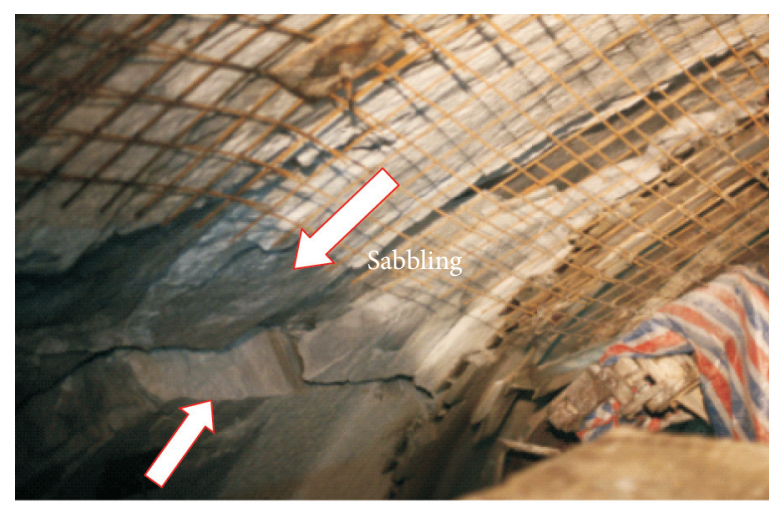

(a)

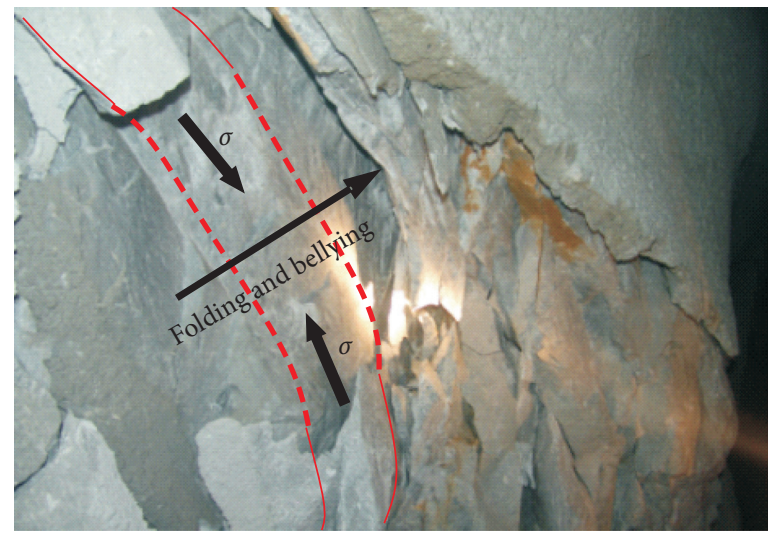

(c)

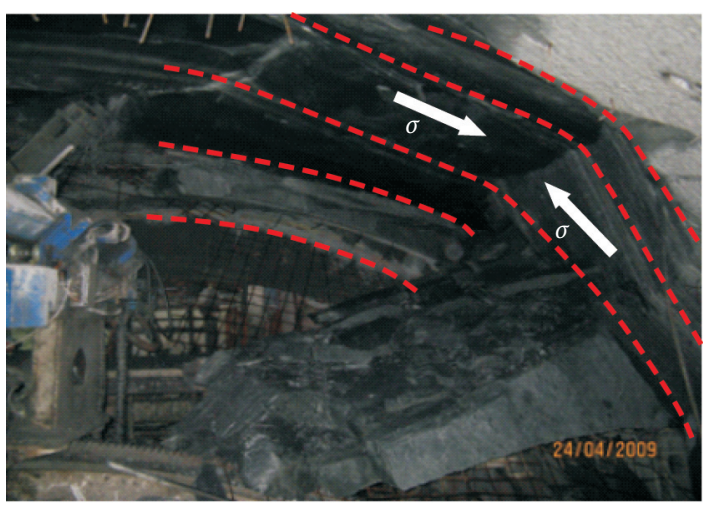

(b)

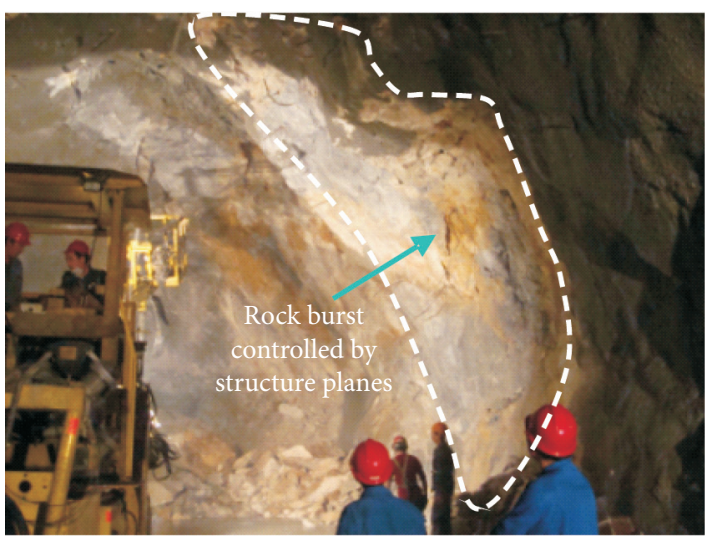

(d)

Figure 8: Typical rock burst failures during the excavation process of $1^{\#} \sim 4^{\#}$ diversion tunnels: (a) extrusion and slabbing on the left arch foot of $1^{\#}$ diversion tunnels (section k14 $318 \sim 328$ ), (b) slabbing caused by stress concentration on the right arch foot of $4^{\#}$ diversion tunnels (section k13 + 255 270), (c) folding and belling on the left sidewall of $1^{\#}$ diversion tunnels (section k14 + 789 800), and (d) structure planes controlled failure on the right arch of $2^{\#}$ diversion tunnels (section $\mathrm{k} 14+580$ ).



(a)

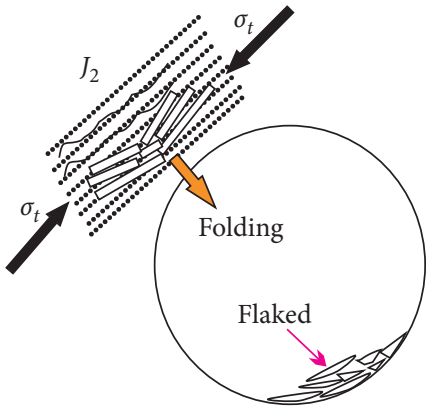

(b)

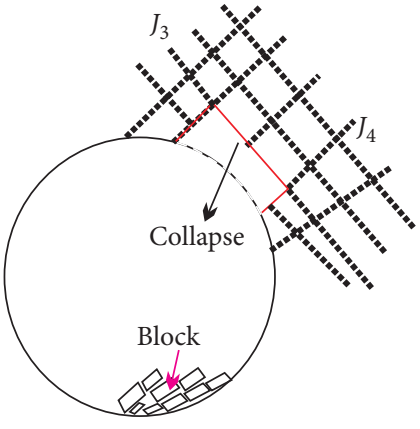

(c)

FIGURE 9: Failure mechanisms of typical rock bursts: (a) extrusion and slabbing, (b) folding and belling, and (c) structure planes controlled failure.

between the deformation body and shear plane in the parent rock mass exceed the shear strength, and dynamic instability is caused by a small disturbance. The elastic strain energy accumulated in the deformation body is released instantaneously, and rockburst occurs. This type of rockburst is often accompanied by a crisp sound, and the rock mass that breaks of is mainly platelike.
The failure process of folding and belling is similar to the mechanical process of extrusion and slabbing failure (Figure 9(b)). However, extrusion and slabbing failure usually occur in the relatively complete areas of the surrounding rock mass, while folding and belling usually occur in surrounding rock masses with developed structural surfaces (such as $J_{2}$ developed in the upper arch shoulder 
with the dip of $10^{\circ}-25^{\circ}$ and the dip direction of $190^{\circ}-210^{\circ}$ ), and the failure of the rock mass is usually flaked or thinplated shape. In addition, the scale and depth of extrusion and slabbing failure are usually larger than those of folding and belling failure. As shown in Figure 9(c), the structural plane controlled failure usually occurs in the area where the structural plane is relatively well developed. The rock mass is cut into relatively independent blocks by the crossing structural planes $J_{3}$ and $J_{4}$ developed in the downstream arch shoulder. After the excavation of the surrounding rock mass, a free surface is formed, and collapse occurs under the action of gravity and unloading deformation. This type of rockburst is usually accompanied by a small dull sound or no sound, and the damaged rock mass is usually blocky.

In addition, there is a link between the EDZ and rockburst. In general, the occurrence of rockburst events is directly related to the continuous relaxation and diffusion in the loose zone. As shown by the results of the acoustic wave test and by the results of the statistical data analysis, the average relaxation depths in tunnels $2^{\#}$ and $4^{\#}$ (excavated by drilling-blasting) were $7.2 \%$ and $8.2 \%$ larger than those in tunnels $1^{\#}$ and $3^{\#}$ (excavated by the TBM), respectively. However, the size of the medium rockburst caused by the TBM method was 2.16 times larger than that caused by the drilling-blasting method, and the size of the minor rockburst caused by the TBM method was 2.28 times larger than that caused by the drilling-blasting method. The larger the range of the EDZ, the smaller the rockburst. This indicates that the cumulative effect of the stress in the surrounding rock caused by TBM excavation is greater than the diffusion effect of the loose zone during excavation.

4.2. Comparative Analysis of the Rockbursts Caused by TBM or the Drilling-Blasting Method. In order to further study the relationship between rockbursts and the different excavation methods, the rockburst events occurring between section $\mathrm{K} 12+000 \mathrm{~m}$ and section $\mathrm{K} 16+000 \mathrm{~m}$ in diversion tunnels $1^{\#}-4^{\#}$ were recorded and analyzed. As shown in Table 1 , according to the rockburst classification standards in GB 50487-2008, rockbursts are divided into four categories: slight, medium, strong, and extremely strong [35]. The sections in which the rockbursts occurred and the proportion of the different categories of rockburst during the excavation of diversion tunnels $1^{\#}-4^{\#}$ between section $\mathrm{k} 12+000 \mathrm{~m}$ and section k16+000 $\mathrm{m}$ are shown in Figures 10 and 11.

As shown in Figures 10 and 11, the medium rockbursts mainly present structural plane controlled failure modes or extrusion and slabbing failure modes. A total of

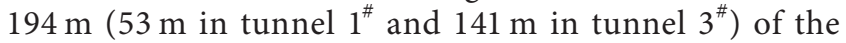
TBM excavated tunnels experienced medium rockbursts, accounting for $4.86 \%$ of the total tunnel length, while $90 \mathrm{~m}\left(21 \mathrm{~m}\right.$ in tunnel $2^{\#}$ and $69 \mathrm{~m}$ in tunnel $\left.4^{\#}\right)$ of the drilling-blasting excavated tunnels experienced medium rockburst, accounting for $2.26 \%$ of the total tunnel length, with the former being 2.16 times larger than the latter. In terms of slight rockbursts, folding and belling failure and extrusion and slabbing failure are the major

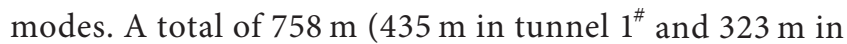
tunnel $3^{\#}$ ) of the TBM excavated tunnels experienced slight rockbursts, accounting for $18.95 \%$ of the total tunnel length, while $333 \mathrm{~m} \mathrm{(220} \mathrm{m} \mathrm{in} \mathrm{tunnel} 2^{\#}$ and $113 \mathrm{~m}$ in tunnel $4^{\#}$ ) of the drilling-blasting excavated tunnels experienced slight rockbursts, accounting for $8.33 \%$ of the total tunnel length, with the former being 2.28 times larger than the latter. In terms of strong rockbursts, only 5 events ( 2 in tunnel $2^{\#}, 1$ in tunnel $1^{\#}$, and 2 in tunnel $2^{\#}$ ) were observed in the 4 tunnels, and they did not follow an obvious statistical rule.

Based on the above statistical analysis, in terms of rockbursts of the same category and characteristics, the number and scale of rockbursts in the tunnel sections excavated using the TBM method were greater than those in the tunnel sections excavated using the drilling-blasting method. Furthermore, the rockbursts have the following characteristics. Slight rockbursts are more common, and the probability, scale, and intensity of the rockbursts gradually increased as the burial depth of the surrounding rock mass increased. The rockbursts mostly occurred in the arch foot, followed by the crown of the surrounding rock mass. During the excavation of the tunnel section with burial depths of greater than $1000 \mathrm{~m}$, the occurrence of peeling and rockbursting was relatively serious. The plate cracking often occurred in the surface layer of the surrounding rock mass, and a small amount of ejection with a depth of $0.5-1 \mathrm{~m}$ occurred, accompanied by a crisp sound. When the burial depth was greater than $1500 \mathrm{~m}$, strong ejection occurred, with a depth of $1-3 \mathrm{~m}$, and it developed deep into the surrounding rock mass. When the burial depth was greater than $2000 \mathrm{~m}$, large-scale rockbursts and high stress-induced collapse were more likely to occur, with strong vibrations and a dull sound. The influence depth was greater than $3 \mathrm{~m}$, which poses a serious threat to TBM excavation and even destroys equipment and engineering structures.

\section{Discussion}

At present, the drilling-blasting and TBM are the main methods of excavating underground caverns. Compared with the drilling-blasting method, the TBM method causes fewer disturbances to the surrounding rock, the degree of damage to the surrounding rock caused by the TBM method is relatively low, and the unloading depth is smaller. The sections excavated using the TBM method are smooth, the quality of the formed surrounding rock mass is high, and the amount of support is reduced. Excavation using the TBM method can be carried out continuously when the longdistance construction is conducted under stable surrounding rock conditions. The construction speed is faster, and the construction period can be shortened, reducing the cost of the project. For super long and deeply buried tunnels extending for long distances through mountains, in which the construction adit is difficult to arrange and the layout cost is high, the TBM method is usually preferred since the drilling-blasting method has difficulty meeting the needs of the construction project. Furthermore, reducing the layout of the construction adit can reduce the disturbance to the 
TABLE 1: Classification of rockbursts [31].

\begin{tabular}{|c|c|c|}
\hline Rock burst grading & Main phenomena and lithologic conditions & $R_{c} / \sigma_{m}$ \\
\hline Slight rockburst (class I) & $\begin{array}{l}\text { Rockbursts occur sporadically in the surface layer of surrounding rock, generally affecting the depth } \\
\text { of } 0.1-0.3 \mathrm{~m} \text {, which has little impact on the construction. }\end{array}$ & $4-7$ \\
\hline Medium rockburst (class II) & $\begin{array}{l}\text { The phenomenon of surrounding rockbursts ejection is obvious, there is a bullet-like shooting clear } \\
\text { burst sound with a certain duration, and the damage range is large with the general impact depth of } \\
\qquad 0.3-1 \mathrm{~m} \text {, which has a certain impact on the construction. }\end{array}$ & $2-4$ \\
\hline Strong rockburst (class III) & $\begin{array}{l}\text { Large bursts of surrounding rock occur, resulting in strong ejection with the phenomena of rock } \\
\text { block catapulting and rock powder spraying and which lasts for a long time. The damage range and } \\
\text { lumpiness are larger, generally affecting the depth of } 1-3 \text { meters, which has a great impact on the } \\
\text { construction safety. }\end{array}$ & $1-2$ \\
\hline $\begin{array}{l}\text { Extremely strong rockburst } \\
\text { (class IV) }\end{array}$ & $\begin{array}{l}\text { Rock burst occurred in the large area of the surrounding rock mass, and large rock brocks were } \\
\text { ejected violently with strong vibration and crosstalk. The damage develops rapidly to the deep, } \\
\text { which general influences more than } 3 \mathrm{~m} \text {, and even the whole tunnel is destroyed. This seriously } \\
\text { affects the construction safety. }\end{array}$ & $<1$ \\
\hline
\end{tabular}

Notes: $R_{c} / \sigma_{m}$ is the rock mass strength/stress ratio, where $R_{c}$ is the saturated uniaxial compressive strength of rock mass and $\sigma_{m}$ is the maximum stress in the surrounding rock mass.

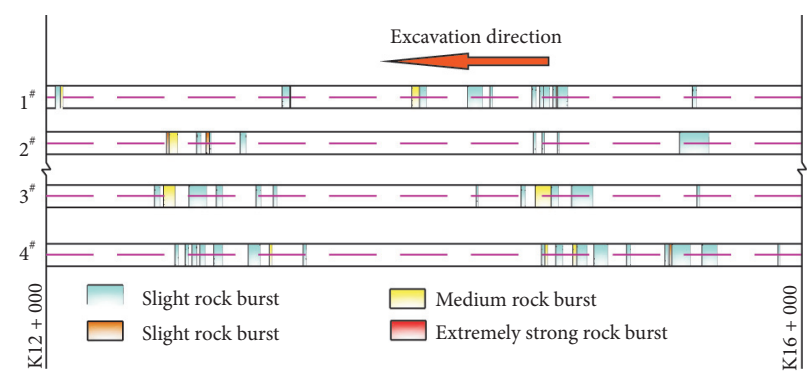

Figure 10: Rock bursts statistics during the excavation of $1^{\#} \sim 4^{\#}$ diversion tunnels between the sections of k12+000 k16 +000 .

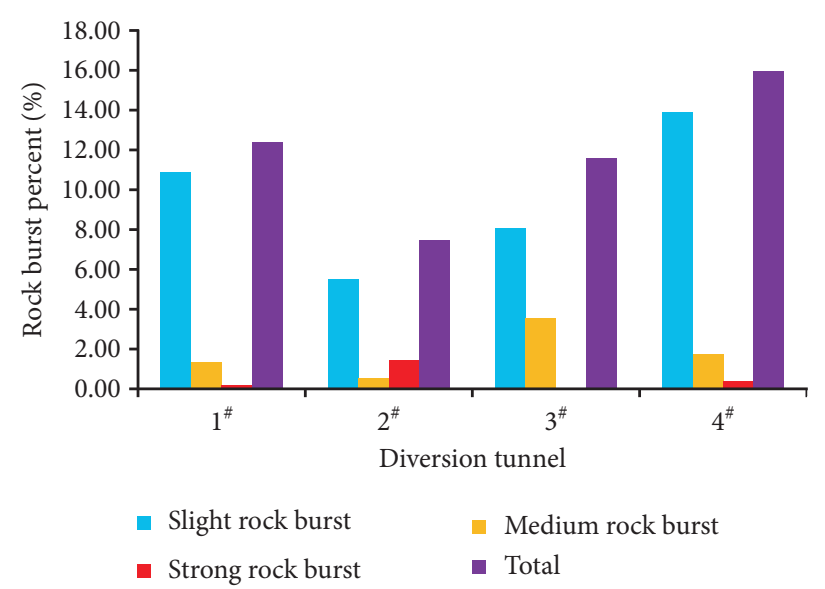

FIGURE 11: Proportion of different categories of rock burst occurred sections during the excavation of $1^{\#} \sim 4^{\#}$ diversion tunnels between the sections of $\mathrm{k} 12+000 \sim \mathrm{k} 16+000$.

original ground, which is conducive to environmental protection. Therefore, over the past 30 years and especially the last 10 years, TBM technology has developed rapidly in China.

However, in high in-situ stress areas, the TBM excavation method may cause other problems, such as strong rockbursts. The construction practice of Jinping II Hydropower Station diversion tunnels shows that, although the
TBM method causes fewer disturbances to the surrounding rock and resulting a lower $\mathrm{EDZ}$, the unloading rate of surrounding rock is also relatively small [17], which avoids serious brittle failure, but the stress is not released in time, which would induce high stress concentration near the edge of excavation and causing wider rockburst events than that using the drilling-blasting method. There were 15 rockbursts with a cumulative section length of $496 \mathrm{~m}$ and 17 rockbursts 


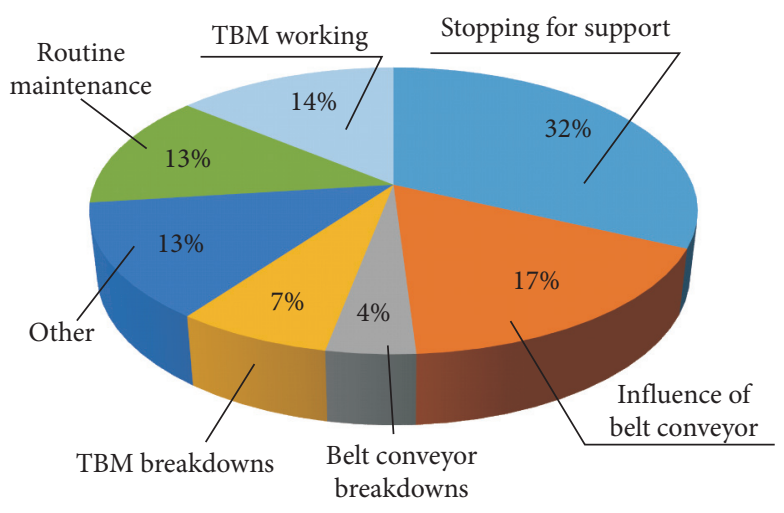

(a)

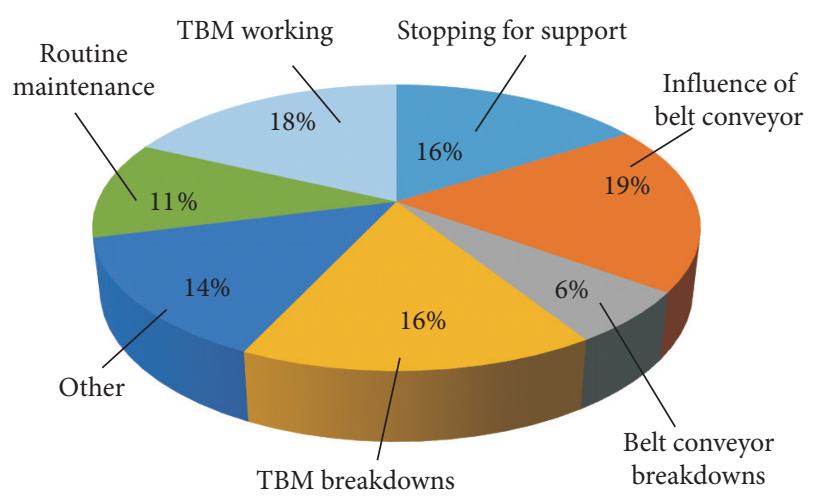

(b)

FIgURE 12: Time distribution chart of TBM construction: (a) $1^{\#}$ diversion tunnel and (b) $3^{\#}$ diversion tunnel.

with a cumulative section length of $464 \mathrm{~m}$ in sections $\mathrm{K} 12+000 \mathrm{~m}$ and $16+000 \mathrm{~m}$ of diversion tunnels $\mathrm{1}^{\#}$ and $3^{\#}$, respectively. The number and scale of rockbursts were larger than in the corresponding drilling-blasting excavation tunnel sections in diversion tunnels $2^{\#}$ and $4^{\#}$. The results indicated that the drilling-blasting method is more prone to structural controlled failure of the surrounding rock mass, while the TBM method would cause more evenly of the EDZ and more widely distributed of stress adjustment induced failure.

The rockbursts led to uneven palm surfaces that damaged the tools of the cutter and the extruding shield of the TBM, resulting in machine clamping and large-scale collapse damaged to the body of the machine. This resulted in only $14 \%$ and $18 \%$ of the effective time being used during the TBM excavation of diversion tunnels $1^{\#}$ and $3^{\#}$ (Figure 12). This reduced the equipment utilization rate and the average tunneling speed. A total of $5859 \mathrm{~m}$ and $6296 \mathrm{~m}$ were excavated by the TBM in 25 and 29 months in diversion tunnels $1^{\#}$ and $3^{\#}$, respectively. The average tunneling advance rate was $234.4 \mathrm{~m} / \mathrm{month}$ and $217.1 \mathrm{~m} / \mathrm{month}$, respectively, and the maximum monthly advance rate was $563 \mathrm{~m}$ and $671 \mathrm{~m}$, respectively. The equipment utilization rate and the tunneling advance rate were far lower than those for similar projects conducted during the same period, e.g., the maximum monthly and daily advance rates of the TBM excavation of the Dahuofang diversion tunnel were $1111 \mathrm{~m} /$ month and $63.5 \mathrm{~m} /$ day, respectively, and this utilization rate of the tunneling operation reached $40 \%$ [36]. The average monthly advance rates of the 4 units used in the Northwest Liaoning Water Supply Project were $622 \mathrm{~m} / \mathrm{month}, 624 \mathrm{~m} /$ month, $639 \mathrm{~m} / \mathrm{month}$, and $646 \mathrm{~m} / \mathrm{month}$, and the equipment utilization rate exceeded $40 \%$ [37].

According to the above analysis and construction practices, the TBM method should be carefully considered for tunnel excavation in high stress areas with burial depths of greater than $2000 \mathrm{~m}$. If the TBM method is selected after comprehensive comparison and selection, the following measures are suggested. (1) The open type TBM support equipment should be improved, personnel protection measures should be provided, bolt support of the exposed surrounding rock should be provided as soon as possible, and the equipment should be maintained in a timely manner. (2) Comprehensive rockburst prediction should be carried out by means of microseismic monitoring positioning prediction technology and surrounding rock property prediction. (3) The pilot tunnel should be excavated using the drilling-blasting method to release the rock mass's stress in advance in the sections with the potential for extremely strong rockbursts. (4) Strong support or systematic support measures should be used.

\section{Conclusions}

In this study, by comparing the EDZ and rockburst of the surrounding rock mass in the Jinping II diversion tunnels excavated using the TBM and drilling-blasting methods, the unloading failure process and the rockburst mechanism are analyzed. The following conclusions were reached:

(1) Both the TBM and the drilling-blasting method induced the EDZ during the tunnel excavation. However, due to the different stress adjustment processes in the surrounding rock mass, the degree of damage to the surrounding rock mass caused by the drilling-blasting method was more serious than that caused by the TBM method.

(2) The EDZ induced by the TBM method was usually distributed evenly along the edge of the excavation surface, while the drilling-blasting method was more likely to cause stress concentration, resulting in a deeper EDZ in local areas.

(3) The drilling-blasting method is more prone to structural controlled failure of the surrounding rock mass, while the TBM method would induce high stress concentration near the edge of excavation and more widely distributed of stress adjustment induced failure. As a result, the scale and frequency of the rockbursts caused by the TBM method were significantly greater than those caused by the drillingblasting method during the excavation of deeply buried tunnels with high in-situ stresses. 
(4) The TBM method should be used carefully for tunnel excavation in high in-situ stress areas with burial depths of greater than $2000 \mathrm{~m}$. If it is necessary to use the TBM method after a comprehensive selection, it is suggested that equipment adaptability improvement, advanced prediction, and prediction technology be used.

\section{Data Availability}

The data used to support the findings of this study are included within the article.

\section{Conflicts of Interest}

The authors declare that they have no conflicts of interest.

\section{Acknowledgments}

The authors gratefully thank the support of the Graduate Student's Research Innovation Foundation of Sichuan University (2018YJSY076) and the Science Foundation for Excellent Youth Scholars of Sichuan University (2013SCU04A07). The authors also thank LetPub (www.letpub.com) for its linguistic assistance during the preparation of this manuscript.

\section{References}

[1] H. B. Li, M. C. Liu, W. B. Xing, S. Shao, and J. W. Zhou, "Failure mechanisms and evolution assessment of the excavation damaged zones in a large-scale and deeply buried underground powerhouse," Rock Mechanics and Rock Engineering, vol. 50, no. 1, pp. 1883-1900, 2017.

[2] Y. F. Chen, H. K. Zheng, M. Wang, J. M. Hong, and C. B. Zhou, "Excavation-induced relaxation effects and hydraulic conductivity variations in the surrounding rocks of a large-scale underground powerhouse cavern system," Tunnelling and Underground Space Technology, vol. 49, pp. 253267, 2015.

[3] H. B. Li, X. G. Yang, X. B. Zhang, and J. W. Zhou, "Deformation and failure analyses of large underground caverns during construction of the Houziyan Hydropower Station, Southwest China," Engineering Failure Analysis, vol. 80, pp. 164-185, 2017.

[4] R. S. Read, "20 years of excavation response studies at AECL's Underground Research Laboratory," International Journal of Rock Mechanics and Mining Sciences, vol. 41, no. 8, pp. 1251-1275, 2004.

[5] F. Wu, J. Liu, T. Liu, H. Zhuang, and C. Yan, "A method for assessment of excavation damaged zone (EDZ) of a rock mass and its application to a dam foundation case," Engineering Geology, vol. 104, no. 3-4, pp. 254-262, 2009.

[6] S. C. Maxwell, R. P. Young, and R. S. Read, "A micro-velocity tool to assess the excavation damaged zone," International Journal of Rock Mechanics and Mining Sciences, vol. 35, no. 2, pp. 235-247, 1998.

[7] Q. Jiang, G. Su, X. T. Feng, G. Chen, M. Z. Zhang, and C. Liu, "Excavation optimization and stability analysis for large underground caverns under high geostress: a case study of the Chinese Laxiwa project," Rock Mechanics and Rock Engineering, vol. 52, no. 3, pp. 895-915, 2019.
[8] Q. Jiang, J. Cui, and J. Chen, "Time-dependent damage investigation of rock mass in an in situ experimental tunnel," Materials, vol. 5, no. 8, pp. 1389-1403, 2012.

[9] T. Sato, T. Kikuchi, and K. Sugihara, "In-situ Experiments on an excavation disturbed zone induced by mechanical excavation in Neogene sedimentary rock at Tono mine, central Japan," Engineering Geology, vol. 56, no. 1-2, pp. 97-108, 2000.

[10] N. R. Barton, TBM Tunnelling in Jointed and Faulted Rock, pp. 3-12, CRC Press, Cleveland, OH, USA, 2000.

[11] A. Lisjak, D. Figi, and G. Grasselli, "Fracture development around deep underground excavations: insights from FDEM modelling," Journal of Rock Mechanics and Geotechnical Engineering, vol. 6, no. 6, pp. 493-505, 2014.

[12] Q. Jiang, B. Yang, F. Yan, C. Liu, Y. Shi, and L. Li, "New method for characterizing the shear damage of natural rock joint based on 3D engraving and 3D scanning," International Journal of Geomechanics, vol. 20, no. 2, pp. 1-15, 2020.

[13] X. Sun, C. Ren, J. Yuan, J. Du, J. Liu, and B. Guo, "The analysis of time-space effect of surrounding rock deformation of TBM tunnels in deep composite stratum with or without support," Advances in Civil Engineering, vol. 2020, Article ID 5494192, 21 pages, 2020.

[14] Q. Jiang, X. T. Feng, T. B. Xiang, and G. S. Su, "Rockburst characteristics and numerical simulation based on a new energy index: a case study of a tunnel at 2,500 m depth," Bulletin of Engineering Geology and the Environment, vol. 69, no. 3, pp. 381-388, 2010.

[15] D. Zhuang, K. Ma, C. Tang, Z. Liang, and Z. Wang, "Microseismic monitoring of energy changes in deep tunnels during the TBM tunneling of the Jinping II hydropower station," Advances in Civil Engineering, vol. 2018, Article ID 5364628, 15 pages, 2018.

[16] Q. Jiang, S. Zhong, P. Z. Pan, Y. Shi, H. Guo, and Y. Kou, "Observe the temporal evolution of deep tunnel's 3D deformation by 3D laser scanning in the Jinchuan No. 2 Mine," Tunnelling and Underground Space Technology, vol. 97, pp. 1-21, 2020.

[17] X. Si and F. Gong, "Strength-weakening effect and sheartension failure mode transformation mechanism of rockburst for fine-grained granite under triaxial unloading compression," International Journal of Rock Mechanics and Mining Sciences, vol. 131, Article ID 104347, 2020.

[18] K. Duan, Y. Ji, W. Wu, and C. Y. Kwok, "Unloading-induced failure of brittle rock and implications for excavation-induced strain burst," Tunnelling and Underground Space Technology, vol. 84, pp. 495-506, 2019.

[19] T. H. Ma, C. A. Tang, L. X. Tang, W. D. Zhang, and L. Wang, "Rockburst characteristics and microseismic monitoring of deep-buried tunnels for Jinping II Hydropower Station," Tunnelling and Underground Space Technology, vol. 49, pp. 345-368, 2015.

[20] L. Liu, X. Wang, Y. Zhang, Z. Jia, and Q. Duan, “Tempospatial characteristics and influential factors of rockburst: a case study of transportation and drainage tunnels in Jinping II hydropower station," Journal of Rock Mechanics and Geotechnical Engineering, vol. 3, no. 2, pp. 179-185, 2011.

[21] X. G. Zhao, J. Wang, M. Cai, C. Cheng, L. K. Ma, and R. Su, "Influence of unloading rate on the strainburst characteristics of beishan granite under true-triaxial unloading conditions," Rock Mechanics and Rock Engineering, vol. 47, no. 2, pp. 467-483, 2013.

[22] H. Xu, X. T. Feng, C. Yang, X. Zhang, Y. Zhou, and Z. Wang, "Influence of initial stresses and unloading rates on the deformation and failure mechanism of Jinping marble under 
true triaxial compression," International Journal of Rock Mechanics and Mining Sciences, vol. 117, pp. 90-104, 2019.

[23] S. Y. Wu, M. B. Shen, and J. Wang, "Jinping hydropower project: main technical issues on engineering geology and rock mechanics," Bulletin of Engineering Geology and the Environment, vol. 69, no. 3, pp. 325-332, 2010.

[24] GB 50287-99, Code for Water Resources and Hydropower Engineering Geological Investigation, Ministry of Construction of the People's Republic of China Press, Beijing, China, 2006.

[25] Z. G. Shan and P. Yan, "Management of rock bursts during excavation of the deep tunnels in Jinping II Hydropower Station," Bulletin of Engineering Geology and the Environment, vol. 69, no. 3, pp. 353-363, 2010.

[26] S. Y. Wu, J. F. Zhou, B. R. Chen, and M. B. Huang, "Effect of excavation schemes of TBM on risk of rockburst of long tunnels at Jinping II Hydropower Station," Chinese Journal of Rock Mechanics and Engineering, vol. 34, no. 4, pp. 728-734, 2015.

[27] N. Barton, Rock Quality, Seismic Velocity, Attenuation and Anisotropy, CRC Press, Cleveland, OH, USA, 2007.

[28] J. H. Deng, C. F. Lee, and X. R. Ge, "Characterization of the disturbed zone in a large rock excavation for the Three Gorges Project," Canadian Geotechnical Journal, vol. 38, no. 1, pp. 95-106, 2001.

[29] DL/T5389-2007, Construction Technical Specifications on Rock-Foundation Excavating Engineering of Hydraulic Structures, Development and Reform Commission of the People's Republic of China Press, Beijing, China, 2007.

[30] E. E. Hoek and T. Brown, Rock Subsurface Engineering, Metallurgical Industry Press, Beijing, China, 1986.

[31] B. F. Russenes, Rock Burst Analysis for Tunnels in Mountain Slopes, Geologisk Institute, Trondheim, Norway, 1974.

[32] W. D. Ortlepp and T. R. Stacey, "Rockburst mechanisms in tunnels and shafts," Tunnelling and Underground Space Technology, vol. 9, no. 1, pp. 59-65, 1994.

[33] L. S. Xu, "Research of rockburst formation condition in underground engineering," Journals of Chongqing Jiaotong University, vol. 24, no. 3, pp. 31-34, 2005.

[34] M. Cai, "Influence of intermediate principal stress on rock fracturing and strength near excavation boundaries-Insight from numerical modeling," International Journal of Rock Mechanics and Mining Sciences, vol. 45, no. 5, pp. 763-772, 2008.

[35] GB 50487-2008, Code for engineering Geological Investigation of Water Resources and Hydropower, Ministry of Housing and Urban Rural Development of the People's Republic of China Press, Beijing, China, 2008.

[36] S. B. Du and Y. Y. DU, "Demonstration and practice of TBM operation scheme in the construction of water conveyance tunnel of Dahuofang reservoir," Water Conservancy and Hydropower Technology, vol. 38, no. 3, pp. 47-49, 2007.

[37] L. J. Du, "China TBM construction technology progress, challenges and countermeasures," Journal of Tunnel Construction, vol. 37, no. 9, pp. 1063-1075, 2017. 